\title{
Alzheimer's disease
}

\author{
P Kist, IR Hastie
}

The equivalent of one paper on the subject of dementia is published every five hours, day and night. Despite this massive research effort, Alzheimer's disease which is probably the cause of dementia in up to half of all cases, ${ }^{1}$ remains an enigma. The aetiology is obscure, diagnosis is still difficult (especially the differentiation of Alzheimer's disease from vascular dementia) and there remain few options for treatment at present. However, our knowledge is increasing.

\section{Aetiology}

Mutations in the $\beta$-amyloid precursor protein gene transmitted as an autosomal dominant are known to be associated with Alzheimer's disease; these have been located on chromosome $21 .{ }^{2}$ More recently a second gene locus has been located on chromosome $14 .^{3,4}$ It is still unknown whether this new locus is also involved in amyloid processing; if this turns out to be the case, then the assumption that $\beta$-amyloid precursor protein mis-metabolism is central in the causation of the disease will be strengthened.

The striking recent finding that a common genetic variant of apolipoprotein $\mathbf{E}$

A

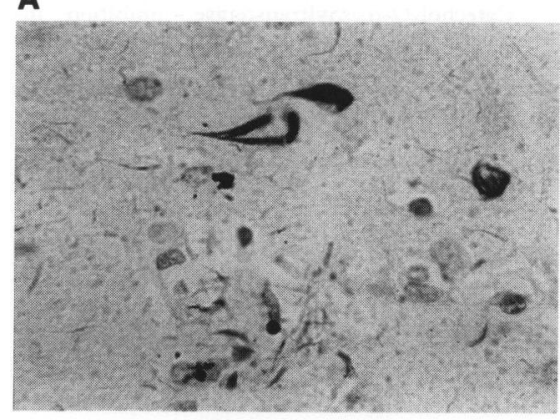

B

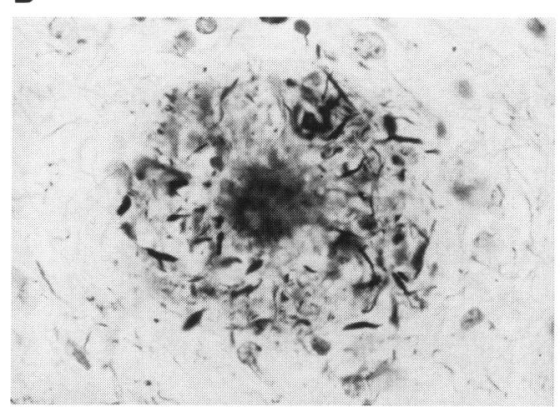

Figure (A) Neurons containing neurofibrillary tangles, (B) senile plaque with an amyloid core, surrounded by dystrophic neurites and glia. (Stain Braak et al. Stain Technol 1989; 63: 197. Photographs courtesy of Dr DC Davies, Department of Anatomy, St George's Hospital Medical School, London)

Division of Geriatric Medicine, St George's Hospital Medical School, London SW17 ORE, UK

P Kist

IR Hastie

Correspondence to IR Hastie

Accepted 8 June 1994 (apo E4) is associated with a high risk of developing late onset Alzheimer's disease will have widespread repercussions. ${ }^{5}$ Twenty-five per cent of the world population carries this allele, and $2-3 \%$ are homozygotes with $90 \%$ penetrance. The gene for apo $\mathrm{E}$ is on chromosome 19 , within the genomic region previously associated with late onset familial Alzheimer's disease. ${ }^{6}$ Apo $\mathrm{E}$ accumulates in amyloid plaques and neurofibrillary tangles. Hopefully, this will lead to new avenues of treatment interfering with the interactions between apo E4 and $\beta$-amyloid precursor protein or even gene therapy. Aluminium is certainly neurotoxic, but has not been shown to be a cause of Alzheimer's disease as yet. ${ }^{7}$

\section{Diagnosis}

The need for accurate and reliable tools to establish an early diagnosis of Alzheimer's disease is becoming ever greater, not only for recruitment to treatment trials but also for individual patient treatment as these become available. The 'gold standard' for diagnosing Alzheimer's disease is post-mortem histopathology or brain biopsy; this is for obvious reasons rarely met. The National Institute of Neurological and Communicative Disorders and Stroke and the Alzheimer's Disease and Related Disorders Association (NINCDS/ ADRDA) $)^{8}$ have developed criteria that are reasonably specific, have excellent sensitivity, and an accuracy rate ranging from $68-100 \%{ }^{9}$

Of the neuro-imaging techniques, computed tomography (CT) scanning of the brain is the most routinely used method. Besides cerebral atrophy and increased cerebrospinal space, linear medial temporal lobe measurements have been shown to be specific for severe dementia but not necessarily for Alzheimer's disease. ${ }^{10,11}$ Magnetic resonance imaging (MRI) scanning is more sensitive because of its higher resolution. Functional neuro-imaging using positionemission tomography (PET) and single photon emission CT (SPECT) scanning are showing early changes of temporo-parietal hypo-metabolism in Alzheimer's disease before neuropsychological deficits become apparent. ${ }^{12}$

A potential biochemical marker in the cerebrospinal fluid (CSF) was described recently ${ }^{13}$ linked to changes in glutamatergic transmission in Alzheimer's disease. Glutamine synthetase was found in the CSF of 38 out of 39 Alzheimer's disease patients, but only in one out of 44 controls. More research in the pathophysiology of this transmitter's metabolism is needed.

\section{Treatment}

CHOLINERGIC ENHANCEMENT

Tetrahydroaminoacridine (tacrine) has now been formally approved in the US by the Food \& Drug Administration for the treatment of symptoms of Alzheimer's disease. The benefit in most studies however, has been only modest, 


\begin{tabular}{|l|}
\hline Recent advances in \\
Alzheimer's disease \\
\hline - not all cases of dementia are due to \\
Alzheimer's disease \\
- some cases of Alzheimer's disease \\
have a genetic origin \\
- the development of Alzheimer's \\
disease is closely related to \\
mis-metabolism of beta amyloid \\
precursor protein \\
- as yet, aluminium has not been \\
shown to be a cause \\
- early changes in cerebral \\
hypometabolism have been \\
demonstrated by PET and SPECT \\
scanning prior to clinical \\
manifestations \\
- avenues of treatment are at last \\
being developed \\
\hline
\end{tabular}

and limited to certain sub-groups of Alzheimer's disease patients. ${ }^{14}$ It is potentially toxic especially to the liver and can also cause nausea, diarrhoea, and a rash, as well as cholinergic side-effects. The other major contender for an effective treatment in Alzheimer's disease is physostigmine which has also been shown to be of some benefit to at least a proportion of patients. ${ }^{15}$

\section{NEUROTROPHIC FACTORS}

Nerve growth factor was first described in the 1950s and now has been shown to have a neuro-protective effect on the neurons of the basal nucleus of Meynert in animal models of Alzheimer's disease, and administered in vivo and in vitro to these neurons it increases the cholinergic output. ${ }^{14}$ Nerve growth factor receptors have been demonstrated in human post-mortem brain and may offer a future avenue for treatment.

Other neurotrophic factors include brain-derived neurotrophic factor and neurotrophin-3; these may well be important to our understanding of Alzheimer's disease and open up possible treatment options.

Gradually our understanding of the aetiology and pathophysiology of Alzheimer's disease is increasing and this is leading to possible avenues of treatment for this devastating disease.

1 Skoog J, Nillsan D, Palmertz B, Andreasson L, Svanborg A. A population-based study of dementia in 85-year olds. $N$ Engl $f$ Med 1993; 328: $153-8$.

2 St George-Hyslop PH, Tanzi RE, Polinksky RJ, et al. The genetic defect causing familial Alzet al. The genetic defect causing familial Alzheimer's disease maps on
Science 1987; 235: 885-9.

3 Mullan M. Familial AD: second gene locus located. $B M \mathcal{F}$ 1992; 305: 1108 .

4 Schellenberg G, Bird T, Wysman E, et al. Genetic linkage evidence for a familial $A D$ locus on chromosome 14. Science 1992; 258: 668-71.

5 Poirier J, Davignon J, Bouthillier D, Kogan S Bertrand P, Gauthier S. Apolipoprotein E polymorphism and AD. Lancet 1993; 342: 697-9.

6 Houlden H, Crook R, Duff K, et al. Confirmation that the apolipoprotein E4 allele is associated with late onset, familial AD. Neurodegeneration 1993; 2: 283-6.

7 Doll R. Review: AD and environmental Doll R. Review: AD and environm

8 McKhann G, Drachman D, Folstein M, KatzMcKhann G, Drachman D, Folstein M, Katzman $R$, Price D, Stadlan EM. Clinical diagnosis
of AD: report of the NINCDS/ADRDA workgroup. Neurology 1984; 34: 939-44.
9 Burns A, Accuracy of clinical diagnosis of AD. Alzheimer's Rev 1992; 2: 25-8.

10 Jobst KA, Smith A, Szatmari M, et al. Detection in life of confirmed AD using simple measurein life of confirmed AD using simple measureLancet 1992; 340: 1179-83.

11 DeCarli C, Kaye J, Horwitz B, Rappoport S. Critical analysis of the use of computer assisted transverse axial tomography to study human brain in aging and dementia of the Alzheimer type. Neurology 1990; 40: 872-83. study of cerebral metabolic asymmetries and associated neuro-psychological patterns in early DAT. Arch Neurol 1990; 47: 753-60.

13 Gunnersen D, Haley B. Detection of glutamine synthetase in the CSF of $A D$ patients: a potential diagnostic biochemical marker. Proc Natl Acad Sci USA 1992; 9: 49-53.

14 Wilcock GK. Recent advances in dementia. In: CA Seymour, AM Haegerty, eds Horizons in medicine vol 4. Maidenhead: McGraw-Hill, 1993.

15 Tune L, Brandt J, Frost JJ, et al. Physostigmine in AD. Acta Psychiatr Scand 1991; 366: suppl
2 Haxby J, Grady C, Koss E, et al. Longitudinal 